\title{
Efek Perbedaan Dataran terhadap Kualitas Litter Closed House Ayam Broiler
}

\author{
Effect of Differences in Plains on Quality of Broiler Chicken Closed House Litter
}

\section{A. S. Hasibuan*, L. D. Mahfudz dan T. A. Sarjana}

Fakultas Peternakan dan Pertanian, Universitas Diponegoro, Kampus Tembalang, Semarang. *Corresponding Author: hasibuan25jr@gmail.com

\begin{abstract}
The study was aimed to examine the effect of the difference in altitude on the quality of the litter in broiler chickens kept in close house cages. The materials used are litter and broiler chickens are maintained in closed house in high, medium and low altitude with the same Standard Operation Procedure (SOP). This study used a completely randomized design (CRD) with 3 treatments and 8 replications. The treatment given is: a cage in the lowlands 0-400 Masl (Meter above sea level) (T1), a cage in the lowlands 400-700 Masl (Meter above sea level) (T2), and a cage in the highlands more than 700 Masl (T3) (Meter above sea level). The parameters tested included ammonia levels, water content, temperature and $\mathrm{pH}$ of the litter, and footpad dermatitis (FPD). Data were processed by analysis of variance with the $\mathrm{F}$ test at a significance level of $5 \%$, if there is any influence the treatment was further tested by Duncan's multiple region test. The results showed that the difference in terrain had a significant effect $(\mathrm{P}<0.05)$ on ammonia levels, $\mathrm{pH}$ of litter and FPD at 14 days, while on litter water content had no significant effect $(\mathrm{P}>0.05)$. Plains difference significantly $(\mathrm{P}<0.05)$ on water content and $\mathrm{pH}$ of litter, however, no significant effect $(\mathrm{P}>0.05)$ on levels of ammonia litter and FPD at 28 days. The conclusion of this study is the difference in terrain has implications for the microclimate of the cage, which affects the quality of the litter (ammonia content, water content, $\mathrm{pH}$ ) and FPD in chickens.
\end{abstract}

Key words: broiler chickens, closed house, ammonia, $\mathrm{pH}$, water content and litter temperature.

\begin{abstract}
ABSTRAK
Penelitian ini bertujuan untuk mengkaji efek ketinggian dataran yang berbeda terhadap kualitas litter ayam broiler yang dipelihara pada kandang closed house. Materi yang digunakan adalah peternakan ayam broiler yang dipelihara di kandang closed house pada dataran tinggi, sedang dan rendah dengan standard operation procedure (SOP) yang sama. Penelitian ini menggunakan rancangan acak lengkap (RAL) dengan 3 perlakuan dan 8 ulangan. Perlakuan yang diberikan yaitu: kandang di dataran rendah 0-400 Mdpl (Meter di atas permukaan laut) (T1), kandang di dataran sedang 400-700 Mdpl (Meter di atas permukaan laut) (T2), dan kandang di dataran tinggi $>700$ Mdpl (Meter di atas permukaan laut) (T3). Parameter yang diuji meliputi kadar amonia, kadar air, suhu dan $\mathrm{pH}$ litter, serta footpad dermatitis (FPD). Data diolah dengan analisis ragam dengan uji $\mathrm{F}$ pada taraf signifikansi 5\%, apabila ada pengaruh perlakuan diuji lanjut dengan uji wilayah ganda Duncan. Hasil penelitian menunjukkan bahwa perbedaan dataran berpengaruh nyata $(\mathrm{P}<0,05)$ meningkatkan kadar ammonia, $\mathrm{pH}$ litter umur 14 hari, sedangkan kadar air litter dan FPD tidak berpengaruh nyata $(\mathrm{P}>0,05)$. Perbedaan dataran berpengaruh nyata $(\mathrm{P}<0,05)$ meningkatkan kadar air dan $\mathrm{pH}$ litter, namun, tidak berpengaruh nyata $(\mathrm{P}>0,05)$ terhadap kadar amonia litter dan FPD pada umur 28 hari. Simpulan dari penelitian ini adalah kualitas litter paling buruk berada pada dataran tinggi sedangkan paling baik pada dataran rendah dilihat dari beberapa aspek yaitu kadar amonia, kadar air, pH dan FPD pada ayam broiler.
\end{abstract}

Kata kunci: ayam broiler, closed house, amonia, $\mathrm{pH}$, kadar air dan suhu litter

\section{PENDAHULUAN}

Perbedaan dataran tempat menyebabkan terjadinya perbedaan kondisi mikroklimat seperti suhu, kelembaban yang berdampak pada mikroklimat didalam kandang close house. Dataran rendah memiliki ketinggian 0 - $400 \mathrm{~m} \mathrm{dpl,}$ dataran sedang $400-700 \mathrm{~m}$ dpl dan dataran tinggi $>700$ m dpl (Istiawan dan Kastono, 2019).

Kandang closed house efektivitas kinerjanya juga tergantung pada input makroklimat meskipun kandang sudah tertutup.
Menurut (Dewanti et al., 2014) bahwa sistem ventilasi tertutup yang seluruh sirkulasi udaranya dapat diatur akan tetapi dipengaruhi oleh lingkungan sekitar.

Perubahan kualitas litter yang terjadi disebabkan oleh kondisi mikroklimat kandang seperti suhu, kelembaban dan kecepatan angin. Penelitian terdahulu melaporkan bahwa mikroklimatik amonia berkorelasi negative terhadap suhu yang menunjukkan adanya penurunan suhu udara berbanding lurus dengan 
kenaikan mikroklimatik amonia (Saputra, et al 2020). Mikroklimatik amonia yang meningkat juga dipengaruhi oleh kecepatan angin dalam kandang ketika kecepatan angin rendah otomatis udara yang masuk dari inlet menjadi lambat terbawa menuju outlet sehingga kurang efektif dalam mengurangi kadar amonia udara. Kadar amonia yang tinggi akan menyebabkan ayam stress, konsumsi pakan menurun dan konsumsi minum meningkat sehingga nantinya ekskreta menjadi encer dan menyebabkan litter cepat basah (Rose, 1997). Kondisi ini memberikan efek terhadap temperatur dan kelembaban kandang, bobot ayam, jumlah udara dalam kandang, stress ayam, penyakit dan perkembangan jamur.

Perubahan mikroklimat akan mempengaruhi dengan kualitas litter berupa suhu litter, $\mathrm{pH}$ litter, kadar air litter yang berdampak terhadap produksi amonia. Kualitas litter pada dataran rendah menunjukkan kadar amonia yang lebih rendah dibandingkan dengan kadar amonia litter yang berada di dataran tinggi sehingga dapat dikatakan bahwa perubahan mikroklimat kandang diiringi dengan adanya perubahan kualitas litter (Lima et al., 2011). Perbedaan makroklimat akan mempengaruhi aliran atau sebaran kadar amonia dalam kandang secara tidak langsung. Menurut (Diyantoro et al., 2018) makroklimat memberikan kontribusi terhadap mikroklimat kandang yang berdampak terhadap perubahan kualitas litter kandang.

Amonia merupakan senyawa yang bersifat basa yang mampu mengakibatkan peningkatan nilai $\mathrm{pH}$ sehingga apabila kadar amonia meningkat maka diikuti dengan adanya kenaikan pH. Menurut (Marang et al., 2019) pH litter $<7$ menurunkan proses pembentukan amonia sedangkan pada $\mathrm{pH}>8$ akan meningkatkan volatilisasi amonia. Suhu dan kelembaban mirkoklimat kandang yang tinggi berpotensi meningkatkan Kadar air litter yang sehingga meningkat produksi amonia hal ini disebabkan aktivitas mikroorganisme meningkat dalam mengurai asam urat menjadi amonia. Menurut (Tucker dan Walker 1992) kadar air litter dipengaruhi oleh suhu dan kelembaban dalam kandang. Kualitas litter yang buruk akan meningkatkan peluang ayam broiler terkena foot pad dermatitis dan berpotensi juga infeksi saluran pernapasan.

Tujuan dari penelitian ini adalah untuk mengkaji efek perbedaan ketinggian dataran terhadap kualitas litter closed house ayam broiler. Manfaat dari penelitian ini yaitu dapat dijadikan sebagai landasan teori untuk mempersiapkan sistem pemeliharaan ayam broiler di kandang closed house untuk periode kedepannya pada dataran yang berbeda. Hipotesis dari penelitian ini adalah pada tiap dataran memiliki makroklimat berbeda yang berimplikasi terhadap mikroklimat kandang, sehingga berpotensi terjadi kualitas litter yang berbeda juga.

\section{MATERI DAN METODE}

Materi yang digunakan pada penelitian yaitu kandang closed house yang berlokasi di dataran rendah, sedang dan tinggi, tiap dataran terdiri dari 2 kandang dengan panjang $120 \mathrm{~m}$ lebar $12 \mathrm{~m}$ kapasitas 22.500 ekor, unisex memiliki ratarata bobot awal 40,61 $\pm 3,31 \mathrm{~g}$, strain Cobb dan menggunakan standar operational procedure (SOP) yang sama dalam pemeliharaan. Penelitian ini dilakuakan selama 28 hari dari periode starter menggunakan litter berbahan sekam padi dengan ketebalan $\pm 5 \mathrm{~cm}$. Alat yang digunakan adalah Infrared untuk mengukur suhu litter, amonia detektor untuk mengukur kadar amonia pada litter, $\mathrm{pH}$ meter untuk mengukur derajat keasaman pada litter

Rancangan percobaan yang digunakan yaitu rancangan acak lengkap (RAL) dengan 3 perlakuan dan 8 kelompok. Perlakuan adalah perbedaan ketinggian letak kandang close house sebagai berikut berikut: T1: kandang pada ketinggian $<400 \mathrm{~m}$ dpl (demak), T2: kandang pada ketinggian 400-700 $\mathrm{m}$ dpl (gunung pati), T3: kandang pada ketinggian $>700 \mathrm{~m} \mathrm{dpl}$ (ampel). Parameter yang diamati adalah kualitas litter meliputi kadar amonia litter, kadar air litter, suhu litter, $\mathrm{pH}$ litter, foot pad dermatitis (FPD). Pengukuran kadar amonia litter menggunakan alat amonia detektor dilakukan dengan pengambilan sampel litter ayam sebanyak $20 \mathrm{~g} / \mathrm{pen}$ setelah itu dimasukkan pada plastik kemudian dimasukkan amonia detector pada plastik yang berisi litter lalu diamati berapa kadar amonianya dan dicatat hasilnya. Metode ini dilakukan berdasarkan modifikasi penelitian (Sarjana et al., 2017)

Beberapa data terkait mikroklimat kandang juga diamati untuk memberikan gambaran kondisi faktual yang terjadi didalam kandang disjaikan pada tabel 1. Pengukuran suhu litter menerapkan metode (Jacob et al., 2016). 
Tabel 1. Rata-rata pengaruh suhu, kelembaban, kecepatan angin, heat index dan wind chill factor

\begin{tabular}{lccc}
\hline \multirow{2}{*}{ Mikroklimat } & \multicolumn{3}{c}{ Rata-rata } \\
\cline { 2 - 4 } & Demak & Gunung pati & Ampel \\
\hline Suhu & $32^{\circ} \mathrm{C}$ & $28^{\circ} \mathrm{C}$ & $28^{\circ} \mathrm{C}$ \\
Kelembaban & $60 \%$ & $77 \%$ & $73 \%$ \\
Kecepatan angin & $2,59 \mathrm{~m} / \mathrm{s}$ & $2,97 \mathrm{~m} / \mathrm{s}$ & $1,74 \mathrm{~m} / \mathrm{s}$ \\
Heat index & 150 & 160 & 157 \\
Suhu efektif & $23^{\circ} \mathrm{C}$ & $22^{\circ} \mathrm{C}$ & $25^{\circ} \mathrm{C}$ \\
Wind chill factor & $10,44^{\circ} \mathrm{C}$ & $11,47^{\circ} \mathrm{C}$ & $6,52^{\circ} \mathrm{C}$ \\
\hline
\end{tabular}

Sumber: Data primer hasil penelitian

*kalkulasi wind chill factor berdasarkan rumus yang dogunakan oleh Zajicek dan Kic (2013)

Pengukuran suhu litter dalam kandang menggunakan alat infrared, pengukuran suhu litter dilakukan dengan cara meletakkan alat infrared pada litter lalu diamati menunjukkan pada suhu berapa dan kemudian dicatat hasilnya. Pengukuran nilai $\mathrm{pH}$ pada litter menerapkan metode (Gracia et al., 2018) menggunakan pH meter dengan cara disiapkan 3 gram litter ditambah aquades sampai $50 \mathrm{ml}$ kemudian dihomogenisasi. Larutan diambil $3 \mathrm{ml}$ taruh ke tube lalu disentrifus (8000 rpm selama 3 menit). Setelah disentrifus diambil cairan lapisan paling atas (supernatan) sebanyak $1 \mathrm{ml}$, lalu ditambah dengan aquades sampai $50 \mathrm{ml}$ diaduk dan diukur pHnya menggunakan $\mathrm{pH}$ lalu dicatat angka berapa menunjukkan pada $\mathrm{pH}$ meter. Pengukuran kadar air dilakukan dengan cara kadar air dalam litter terlebih dahulu diukur dengan mengubah litter menjadi bahan kering kemudian sampel litter di oven agar dapat diketahui berat keringnya. Hasil perhitungan kadar air dapat dilakuakan dengan menghitung selisih antara berat basah dan berat kering dibagi berat basah dikali $100 \%$ (AOAC, 2005).

Pengukuran FPD dilakukan dengan cara pengamatan pada telapak kaki ayam dengan mengecek lesi lalu diberi score dengan menggunakan metode (Mayne et al., 2006) pengukuran dilakukan dilakukan dengan cara pengamatan pada alas atau bantalan kaki ayam tiap minggunya mulai minggu $1,2,3$ dan 4 . Penilaian atau scoring berdasarkan tingkat keparahan lesi pada kaki ayam yang mengacu pada (Hocking et al., 2008). Data hasil penelitian di analisi ragam menggunakan Analysis of variance (ANOVA) dengan uji $\mathrm{F}$ pada taraf uji $5 \%$ data yang menunjukkan perbedaan nyata, diuji lanjut dengan uji Jarak Berganda Duncan.

\section{HASIL DAN PEMBAHASAN}

\section{Kualitas litter umur 14 hari}

Kadar amonia, $\mathrm{pH}$, kadar air, footpad dermatitis (FPD) umur 14 hari tertera pada tabel 2. Hasil penelitian menunjukkan bahwa perbedaan dataran berpengaruh nyata $(\mathrm{P}<0,05)$ terhadap kadar amonia litter, $\mathrm{pH}$ litter, suhu litter sedang kadar air litter dan FPD tidak berbeda nyata $(\mathrm{P}>0,05)$. Analisis ragam litter pada umur 14 hari terhadap kadar amonia $\mathrm{pH}$, suhu litter dan FPD berbeda nyata $(\mathrm{P}<0,05)$. Hasil analisis Duncan menunjukan bahwa kadar amonia dan $\mathrm{pH}$ berbeda nyata $(\mathrm{P}<0,05)$ lebih rendah pada dataran rendah (Demak) dan dataran sedang (Gunung pati) dibanding dataran tinggi (Ampel). Hal ini akibat suhu efektif, kelembaban dan heat index yang dicapai pada dataran rendah lebih baik dari dataran tinggi (Ampel) seperti terlihat pada Tabel 1.

Tabel 2. Kadar amonia, pH, dan kadar air litter, suhu litter, foot pad dermatitis (FPD) umur 14 hari

\begin{tabular}{|c|c|c|c|c|c|}
\hline \multirow{2}{*}{ Parameter } & \multirow{2}{*}{ Umur (hari) } & \multicolumn{3}{|c|}{ Rata-rata } & \multirow{2}{*}{ P. Value } \\
\hline & & $\mathrm{T} 1$ & T2 & T3 & \\
\hline Kadar Amonia & 14 & $5.13^{\mathrm{b}}$ & $5,19^{\mathrm{b}}$ & $6,63^{\mathrm{a}}$ & 0,03 \\
\hline $\mathrm{pH}$ & 14 & $7,32^{b}$ & $7,11^{\mathrm{c}}$ & $7,66^{\mathrm{a}}$ & $<.0001$ \\
\hline Kadar Air & 14 & 31,62 & 29,56 & 22,85 & 0,54 \\
\hline FPD & 14 & 0,95 & 1,16 & 0,90 & 0,07 \\
\hline \multirow[t]{4}{*}{ Suhu } & 14 & & & & \\
\hline & Pagi & $29,33^{a}$ & $28,28^{\mathrm{b}}$ & $28,35^{\mathrm{b}}$ & 0,03 \\
\hline & Siang & $31,85^{\mathrm{a}}$ & $30,17^{\mathrm{b}}$ & $29,53^{\mathrm{c}}$ & $<.0001$ \\
\hline & Sore & $30,91^{\mathrm{a}}$ & $29,56^{\mathrm{b}}$ & $29,53^{\mathrm{b}}$ & 0,00 \\
\hline
\end{tabular}

Keterangan: Superskrip yang berbeda pada baris yang sama menunjukkan berbeda nyata $(\mathrm{p}<0,05)$ 


\section{Kadar Amonia Litter}

Kadar amonia litter umur pemeliharaan 14 hari pada dataran berbeda mengalami peningkatan yang signifikan $(\mathrm{P}<0,05)$. Peningkatan kadar amonia diduga karena suhu rendah pada dataran tinggi yang dapat mempengaruhi kelembaban mikroklimat kandang. Merujuk pada hasil Penelitian Wahyuningrum (2020) bahwa kondisi mikroklimat pada tiap jenis dataran yang berbeda ditentukan oleh komponen makroklimat seperti kelembaban udara maupun kecepatan angin. Hasil penelitian yang telah kami lakukan diketahui bahwa kadar amonia litter pada dataran tinggi lebih tinggi dibandingkan dengan dataran sedang dan rendah diduga karena dipengaruhi kondisi mikroklimat kandang. Elliot dan Collins (1982) melaporkan bahwa $\mathrm{pH}$, suhu, dan kadar air dapat mempengaruhi laju pembentukan amonia. Sementara itu, faktor penentu lainnya yang diduga berkontribusi terhadap peningkatan kadar amonia adalah kelembaban dan kecepatan angin dalam kandang. Penelitian Saputra et al. (2020) menunjukkan bahwa peningkatan kelembaban (RH) dan kecepatan angin (AV) akan diikuti oleh peningkatan kadar amonia litter. Tingkat eleminasi amonia dalam kandang berhubungan erat dengan suhu, heat index (HI) dan kecepatan angin, pada penelitian yang kami lakukan nilai HI yang ideal dapat dicapai dengan beberapa penyesuai suhu, RH dan kecepatan angin sebagaimana yang disajikan pada tabel 1. Nilai HI pada dataran sedang dan tinggi lebih besar dibandingkan dengan dataran rendah pada kondisi suhu dan RH yang berbeda pula, sehingga akan dikompensasi dengan perubahan kecepatan angin secara berbeda juga. Nilai HI dataran tinggi lebih rendah dari dataran sedang mengakibatkan penyesuain kecepatan angin yang lebih rendah pada dataran tinggi kondisi tersebut berdampak pada tingkat eleminasi amonia yang rendah sehingga pada dataran tinggi terjadi penurun kecepatan angin didalam kandang.

Kecepatan angin yang lebih lambat pada dataran tinggi mengakibatkan penurunan wind chill effect dari $10,44^{\circ} \mathrm{C}$ menjadi $6,52^{\circ} \mathrm{C}$ Kondisi tersebut diduga akibat inefisiensi heat lose dan peningkatan potensi stress akibat cekaman panas. Akibatnya pengeluaran nitrogen yang berada dalam kandang menjadi lambat sehingga amonia dalam kandang meningkat. Menurut Sandyawan dan Putra (2019) temperatur ideal kandang dapat dicapai dengan nilai kecepatan udara yang sesuai, kecepatan udara dalam kandang dapat memberikan efek wind chill sehingga temperatur yang dirasakan ayam lebih kecil dari suhu lingkungan terukur sehingga diperlukan pengaturan yang sesuai. Semakin besar jumlah asam urat ekskreta maka berhubungan semakin tingginya kadar amonia pada dataran tinggi sebagaimana yang tersaji pada tabel 2 .

\section{pH Litter}

Pada penelitian yang telah kami lakukan bahwa $\mathrm{pH}$ litter pada umur pemiliharaan 14 hari mengalami peningkatan $(\mathrm{p}<0,05)$ pada dataran berbeda yang berada pada angka 7,11-7,66. Peningkatan $\mathrm{pH}$ diduga meningkatankan aktivitas bakteri eurolitik dalam menghasilkan amonia yang dipicu kondisi lingkungan pada tiap perbedaan tinggi dataran. Amonia merupakan senyawa yang bersifat basa sehingga mampu membawa dampak terhadap peningkatan $\mathrm{pH}$ litter. Perbedaan RH (kelembaban) pada tiap dataran juga ikut serta dalam mempengaruhi perubahan $\mathrm{pH}$ litter. Kelembaban yang tinggi mengakibatkan kondisi litter menjadi basa sehingga memicu aktivitas mikroorganisme dalam pembentukan amonia. (Saputra et al., 2019) menyatakan bahwa kelembaban yang tinggi menimbulkan litter menjadi lembab sehingga meningkatkan aktivitas bakteri dalam mengurai asam urat menjadi amonia, semakin tinggi kadar amonia litter maka $\mathrm{pH}$ litter juga meningkat. Data Heat Index pada tabel 1. Menunjukkan ayam broiler pada dataran sedang dan tinggi berada pada kondisi yang tidak nyaman yang disebabkan oleh nilai Heat Index $>150$. Hal tersebut berpotensi menimbulkan terjadinya by pass $\mathrm{N}$ menjadi lebih besar sehingga berpengaruh terhadap peningkatan jumlah $\mathrm{N}$ yang diikuti dengan kenaikan jumlah amonia dan $\mathrm{pH}$ litter.

\section{Kadar air litter}

Hasil analisis ragam menunjukkan bahwa kadar air litter pada umur 14 (tabel 2.) yang dipelihara pada dataran berbeda tidak berbeda nyata $(\mathrm{P}>0,05)$. Stress panas pada ayam broiler akan meningkatkan konsumsi air minum untuk menjaga suhu tubuh akibatnya ekskreta akan lebih encer dan basah serta menyebabkan kondisi litter lebih mudah lembab sehingga berpotensi menjadikan kadar air litter menjadi tinggi. Kadar air merupakan salah satu faktor yang mempengaruhi peningkatan amonia. Coufal et al. (2006) menyatakan bahwa kelembaban mempengaruhi volatilisasi NH3. Kondisi pada nilai $\mathrm{pH}<7$ dapat menurunkan proses pembentukan amonia sedangkan pada $\mathrm{pH}>8$ dapat meningkatkan volatilisasi amonia. 
Hal tersebut diduga terjadi karena uric acid memiliki karakteristik basa lemah sehingga apabila amonia meningkat maka diikuti dengan peningkatan $\mathrm{pH}$. Namun, nilai kadar air litter yang dihasilkan pada umur 14 belum memberikan pengaruh yang kuat dalam peningkatan kadar amonia.

\section{Suhu litter}

Hasil penelitian menunjukkan rataan suhu litter umur 14 hari di ketiga dataran berbeda nyata $(\mathrm{P}<0,05)$ berada pada angka $30,7^{\circ} \mathrm{C}$ (Demak); $29,4^{\circ} \mathrm{C}$ (Gunung pati); $29,1^{\circ} \mathrm{C}$ (Ampel). Ini menunjukkan bahwa kondisi suhu litter pada ayam broiler berada pada angka ideal. Menurut Marang et al. (2019) kondisi nyaman suhu litter pada ayam broiler berkisar $29^{\circ} \mathrm{C}-31^{\circ} \mathrm{C}$. Suhu litter paling tinggi berada di dataran rendah sedangkan paling rendah berada di dataran tinggi. Ini menunjukkan bahwa semakin rendah dataran dalam pemeliharaan ayam broiler maka suhu litter akan semakin meningkat begitu juga sebaliknya. Adapun faktor yang mempengaruhi kondisi suhu litter yaitu tingkat kadar amonia dalam litter, suhu udara dalam kandang, sistem ventilasi dan kepadatan kandang. Berdasarkan penelitian yang telah kami lakukan bahwa perubahan suhu litter paling efektif diakibatkan oleh suhu dalam kandang. Hal ini seusai dengan pendapat Saputra et al. (2020) suhu litter berkorelasi positif kuat dengan suhu dan THI, sebaliknya ada kelembaban (RH) dan kecepatan angin (AV) berkorelasi negatif.

\section{Foot pad dermatitis}

Analisis ragam menunjukkan bahwa FPD (foot pad dermatitis) tidak berbeda nyata $(\mathrm{P}>0,05)$ terhadap dataran yang berbeda. Kualitas litter pada umur 14 hari belum menyebabkan muncul foot pad dermatitis pada ayam broiler, ini menunjukkan bahwa ayam broiler masih dalam kondisi nyaman, meskipun kadar amonia, $\mathrm{pH}$, kadar air litter sudah mulai meningkat akan tetapi belum sampai memberikan pengaruh terhadap kesehatan ayam broiler. Pengolahan Kualitas litter yang yang tidak baik dapat berpotensi menimbulkan FPD pada ternak Sulaibah, et al., (2019). FPD merupakan salah satu indikator kesejahteraan ayam broiler. Ayam stres mengakibatkan konsumsi air meningkat dan litter menjadi lembab. Litter yang lembab berpotensi terjadinya FPD. Konsumsi air minum yang tinggi akan berpengaruh terhadap kadar air litter, Kandungan unsur $\mathrm{N}$ dalam ekskreta akan diubah menjadi amonia oleh bakteri dalam kandang) yang akan berpengaruh terhadap kesehatan broiler Metasari et al., (2014).

\section{Kualiatas litter umur 28 hari}

Kadar amonia, $\mathrm{pH}$, kadar air litter, suhu litter dan foot pad dermatitis umur 28 hari, pada ayam yang dipelihara pada dataran rendah, sedang dan tinggi tertera pada Tabel 3. Pada pemeliharaan umur 28 hari kadar amonia litter dan FPD tidak berbeda nyata $(\mathrm{P}>0,05)$ sedangkan $\mathrm{pH}$, suhu litter dan kadar air litter berbeda nyata.

\section{Kadar amonia litter}

Pada pemeliharaan umur 28 hari amonia dalam litter semakinj tinggi hal ini dikarena terdeposisnya eksreta dalam litterdan terdegrdasi oleh bakteri pembusuk menjadi amonia sehingga baik di dataranrendah (Demak), dataran sedang (G. Pati) dan dataran tinggi (Ampel) kadar amonianya menjadi tinggi, sehingga di ketiga dataran tidak berbeda nyata. Pada tabel 2 menunjukkan bahwa kondis ayam broiler pada dataran sedang dan tinggi mengalami stress panas sehingga menyebabkan ayam broiler meningkatkan water intake dan penurunan feed intake akibatnya luaran ekskreta yang dihasilkan encer Ketika bercampur dengan litter menyebabkan litter menjadi lembab sehingga mengalami kenaikan jumlah $\mathrm{N}$ dan menyebabkan aktivitas mikroorganisme semakin tinggi.

Tabel 3. Kadar amonia, pH, dan kadar air litter, suhu litter, foot pad dermatitis (FPD) umur 28 hari

\begin{tabular}{lccccc}
\hline \multirow{2}{*}{ Parameter } & \multirow{2}{*}{ Umur (hari) } & \multicolumn{3}{c}{ Rata-rata } & \multirow{2}{*}{ P. Value } \\
\cline { 3 - 5 } & & $\mathrm{T} 1$ & $\mathrm{~T} 2$ & $\mathrm{~T} 3$ & \\
\hline Kadar Amonia & 14 & 13,11 & 14,44 & 14,94 & 0,27 \\
pH & 14 & $7,59^{\mathrm{b}}$ & $7,10^{\mathrm{c}}$ & $8,13^{\mathrm{a}}$ & $<.0001$ \\
Kadar Air & 14 & $46,42^{\mathrm{a}}$ & $30,22^{\mathrm{b}}$ & $22,86^{\mathrm{c}}$ & $<.0001$ \\
FPD & 14 & 2,29 & 2,19 & 2,42 & 0,38 \\
\hline Suhu & 14 & & & & \\
\hline & Pagi & $29,10^{\mathrm{a}}$ & $27,90^{\mathrm{b}}$ & $29,44^{\mathrm{a}}$ & 0,01 \\
& Siang & $32,35^{\mathrm{a}}$ & $30,45^{\mathrm{c}}$ & $31,44^{\mathrm{b}}$ & $<.0001$ \\
& Sore & $30,71^{\mathrm{a}}$ & $29,24^{\mathrm{b}}$ & $29,57^{\mathrm{b}}$ & 0,00 \\
\hline
\end{tabular}

Keterangan: Superskrip yang berbeda pada baris yang sama menunjukkan berbeda nyata $(\mathrm{p}<0,05)$ 
Maliselo dan Mwaanga (2016) melaporkan bahwa bercampurnya $\mathrm{N}$ eskreta dan litter yang didukung dengan kondisi kelembaban yang tinggi membawa dampak terhadap peningkatan laju pembentukan uric acid yang memicu terjadinya volatilisasi amonia yang tinggi oleh mikroorganisme. Kadar amonia litter yang dihasilkan pada penelitian ini tergolong dalam ambang batas normal. Didukung oleh penelitian Zuprizal. (2009) yang menyatakan bahwa kadar ammonia 15-20 ppm masih mampu untuk menciptakan suasana nyaman dan tidak mengganggu kondisi ayam.

\section{pH litter}

Nilai $\mathrm{pH}$ litter pada dataran berbeda pada umur 28 hari (tabel 4) berbeda nyata $(\mathrm{P}>0,05)$. Nilai $\mathrm{pH}$ litter pada dataran rendah dan sedang nilainya lebih rendah dari dataran tinggi. Hal ini diduga nilai kadar amonia litter yang meningkat, $\mathrm{N}$ yang di hasilkan ekskreta bercampur dengan litter memicu peningkatan $\mathrm{pH}$. Menurut Saputra et al., (2020) Kandungan N ekskreta yangtinggi pada litter dapat meingkatan $\mathrm{pH}$ litter. $\mathrm{pH}$ litter pada umur 28 hari 7,10 -8,13 ini menunjukkan bahwa kondisi $\mathrm{pH}$ litter sudah mulai memburuk karena berpotensi memicu pembentukan amonia. Pada saat $\mathrm{pH}$ litter $>8$ dapat meningkatkan volatilisasi amonia karena uric acid memiliki kaarakteristik basa lemah sehingga ketika amonia meningkatkan maka $\mathrm{pH}$ juga akan meningkat, kondisi $\mathrm{pH}$ litter yang baik yaitu $\mathrm{pH}<7$ karena dapat menurunkan proses pembentukan amonia. Menurut Marang et al. (2019) menayatakan bahwa $\mathrm{pH}>8$ akan meningkatkan volatilisasi amonia sebaliknya pada $\mathrm{pH}<7$ menurunkan volatilisasi amonia. Kelembaban udara juga ikut berkontribusi dalam peningkatan $\mathrm{pH}$. Menurut Liu et al., (2007) Kandang yang lembab berpotensi menyebabkan litter menjadi lembab sehingga aktivitas bakteri dalam mengoversi uric acid menjadi amonia semakin cepat akibatnya kadar amonia akan meningkat dan berimplikasi terhadap peningkatan $\mathrm{pH}$ litter.

\section{Kadar air litter}

Kadar air litter pada umur 28 hari seperti terlihat pada Tabel 3. berbeda nyata $(\mathrm{P}<0,05)$ terhadap dataran Pada dataran rendah (Demak) kadar air litternya lebih tinggi $(\mathrm{P}<0,05)$ dibanding dataran sedang (G Pati), demikian pula dataran sedang ( $\mathrm{G}$ pati) lebih tinggi $(\mathrm{P}<0,05)$ dari dataran tinggi (Ampel). Hal ini dapat dimengerti bahwa dataran rendah dengan temperatur tinggi $\left(32^{\circ} \mathrm{C}\right)$ disajikan pada (tabel 1) membutuhkan banyak air untuk membasahi cooling pad dibanding dataran sedang (G pati) apalagi dataran tinggi (Ampel), sehingga kadar air litter menjadi tinggi di dataran rendah (Demak). Menurut Tucker dan Walker. (1992) menyatakan bahwa kadar air dipengaruhi oleh ventilasi dan sistem manajemen air minum. Untuk menjaga kadar amonia agar tidak meningkat maka kadar air dalam litter harus rendah karena ketika kadar air litter meningkat aktivitas mikroorganisme akan meningkat mengurai uric acid menjadi amonia. Faktor lain yang meningkatkan kadar air litter yaitu akibatkan stress panas sehingga ayam broiler akan meningkatkan konsumsi air minum untuk termoregulasi tubuh akibatnya ekskreta yang dihasilkan menjadi encer sehingga pada saat bercampur dengan litter menjadi lembab. Menurut Sims dan Wolf. (1994) menyatakan bahwa kadar air dapat mempengaruhi tingkat konversi asam urat menjadi ammonium-N. Litter yang basa akan meningkat kadar amonia yang tinggi sehingga berpotensi mengganggu kesehatan pada ayam seperti infeksi saluran pernapasan dan foot pad dermatitis, untuk menekan kadar amonia yaitu kondisi litter harus kering karena dapat menghambat aktivitas enzimatik Kadar air litter dari ketiga dataran berkisar $46,42 \%, 30,22 \%$, $23,86 \%$ ini menunjukkan bahwa kadar air litter pada dataran tidak berada diangka normal. Menurut Metasari et al., (2014) kadar air litter normal berada pada angka $20 \%-25 \%$.

\section{Suhu litter}

Hasil penelitian menunjukkan bahwa suhu litter umur 28 hari di ketiga dataran berbeda nyata $(\mathrm{P}<0,05)$ berada pada angka $30,7^{\circ} \mathrm{C}($ Demak $) ; \quad 29,2^{\circ} \mathrm{C}\left(\right.$ Gunungpati); $30,4^{\circ} \mathrm{C}$ (Ampel). Ini menunjukkan bahwa kondisi suhu litter pada ayam broiler berada pada angka ideal. Menurut Marang et al. (2019) kondisi nyaman suhu litter pada ayam broiler berkisar $29^{\circ} \mathrm{C}-31^{\circ} \mathrm{C}$. Faktanya pada ketiga dataran memiliki kadar amonia yang berbeda dimana dataran rendah cenderung lebih rendah hal ini dapat disebabkan oleh tingkat ventilasi pada dataran rendah lebih banyak bekerja sehingga kadar amonia dalam kandang banyak di keluarkan. Hal ini sesuai pendapat Carr et al. (1990) menyatakan bahwa kinerja ventilasi yang tingggi akan mempengaruhi jumlah udara yang dikeluarkan lebih banyak akan mengencerkan amonia yang dilepas sehingga menghasil kadar amonia lebih rendah. Faktor lain yang mempengaruhi suhu litter yaitu Kondisi mikroklimat kandang seperti suhu dan kelembaban udara pada dataran rendah kondisi makroklimat yang lebih panas dibandingkan 
T2 dan T3 akan berimplikasi pada input mikroklimat kandang sehingga mempengaruhi suhu litter. Hal ini sesuai dengan pendapat Sarjana et al. (2018) menyatakan bahwa suhu udara yang meningkat akan berimplikasi terhadap suhu litter yang meningkat karena terjadinya perpindahan panas secara konveksi dari udara ke litter. Didukung oleh penelitian Wahyuningrum. (2020) yang menyatakan bahwa komponen radiasi matahari memberikan pengaruh terhadap suhu mikroklimat pada dataran rendah (Demak) dan dataran tinggi (Ampel).

\section{Foot pad dermatitis}

Berdasarkan tabel 3. Menunjukkan bahwa foor pad dematitis (FPD) pada umur 28 hari tidak berbeda nyata $(\mathrm{P}>0,05)$. Hal ini diduga terdeposisnya eksreta dalam litter dan terdegrdasi oleh bakteri pembusuk menjadi amonia baik di dataran rendah (Demak), dataran sedang (Gunung Pati) dan dataran tinggi (Ampel) kadar amonianya menjadi tinggi, sehingga di ketiga dataran tidak berbeda nyata, karena amonia yang tinggi di ketiga dataran tersebut menjadikan kejadian FPD menjadi semakin tinggi. FPD (foot pad dermatitis) dipengaruhi faktor terkait dengan kualitas litter seperti amonia kadar air, $\mathrm{pH}$. Menurut Martins et al., (2013) foot pad dermatitis banyak dipengaruhi faktor diantaranya kualitas litter seperti amonia, kadar air, $\mathrm{pH}$ suhu dan kelembaban. Kadar amonia litter tinggi menunjukkan kondisi litter yang buruk yang dipengaruhi oleh $\mathrm{pH}$ litter dan kelembaban sehingga berpotensi munculnya foot pad dermatitis. Menurut Maliselo dan Mwaanga (2016) menyatakan bahwa peningkatan kadar amonia litter dapat dipengaruhi oleh kelembaban dan $\mathrm{pH}$ litter.

\section{KESIMPULAN}

Kesimpulan dari penelitian ini adalah kualitas litter paling buruk berada pada dataran tinggi sedangkan paling baik pada dataran rendah dilihat dari beberapa aspek yaitu kadar amonia, kadar air, pH dan FPD pada ayam broiler. Hal ini dipengaruhi oleh. kondisi makroklimat (suhu, kelembaban, kecepatan angin, radiasi matahari) yang berbeda menjadikan mikroklimat kandang (suhu, kelembaban, kecepatan angin) berbeda yang berimplikasi terhadap kondisi litter ayam broiler yang dipelihara di dalam kandang closed house.

\section{DAFTAR PUSTAKA}

AOAC. 2005. Association Official Analitycal Chemistry. Edisi ke-18. Washington D.C.: Maryland

Carr, L E., F. W. Wheaton dan L. W. Douglass. 1990. Empirical models determine ammonia concentrations from broiler chicken litter. J. ASEA. 33(4): 1337-142.

Coufal, C D., C Chavez., P. R. Niemeyer dan J. B. Carey. 2006. Nitrogen emissions from broiler measured by mass balance over eighteen consecutive flocks. J. Poultry Sci. 85(2): 384-391.

Dewanti, A. C., P. E. Santosa dan K. Nova. 2014. Pengaruh berbagai jenis bahan liter terhadap respon fisiologis broiler fase finisher di close house. J. Ilmiah Peternakan Terpadu 2(3): $81-87$

Diyantoro. F. A., T. A. Sarjana dan W. Sarengat. 2018. Changes in ammonia emmisions in different zonation on closed house in the dry season affects Broiler chicken meat quality. J. Anim. Res App. Sci.

Elliot, H. A dan N. E. Collins. 1982. Factors affecting ammonia release in broiler hauses. J. ASEA. 25(2): 413-424.

Efendi. D. 2010. Peforma dan Respon Fisiologi Ayam Broiler yang Diberi Eansum Mengandung 1,5\% Ampas Buah Merah (Pandanus Conoideus) pada Waktu Pemberian dan Suhu Kandang yang Berbeda. Tesis. Institut Pertanian Bogor. Bogor.

Gracia, R. G., N. D. Lima., A. I. Naas., R. Fabiana., Caladara dan S. Sgavioli. 2018. Thetypology of broiler house and the impact in the locomotion of broilers. J. Engenharia Agricola.38(3): 326-333.

Hocking, P. M., R. K. Mayne., R. W. Else., N. A. French., dan J. Gatclife. 2008.Standard european footpad dermatitis scoring system for use in turkey processing plants. J. World's Poultry Sci. 64 (10): 323-328.

Istiawan dan Kastono. 2018. Pengaruh Ketinggian Tempat Tumbuh terhadap Hasil dan Kualitas Minyak Cengkih (Syzygium aromaticum (L.) Merr. dan Perry.) di Kecamatan Samigaluh, Kulon Progo. J. Vegatalika 8 (1): 27-41. 
Jacob, F. G., M. D. Baracho., I. A. Naas., R. Souza., dan D. A. Salgado. 2016. The use of infrared thermography in the identification of foot pad dermatitis in broilers. J. Engemharia Agricola.36(2): 253-259.

Kaukonen, E., M. Norring dan A. Valros. 2016. Effect of litter quality on foot pad dermatitis, hock burns and breast blisters in broiler breeders during the production period. J. Avian Pathology 45(6): 667-673.

Lima, K. A.O., D.J. Moura, T.M.R. Carvalho, L.G.F. Bueno and R.A. Vercellino. 2011. Ammonia emissions in tunnel-ventilated broiler houses. Brazillian Journal of Poultry Science 13(4): 265-270.

Liu, Z., L. Wang, D. Beasley and E. Oviedo. 2007. Effect of moisture content on ammonia emissions from broiler litter: A laboratory study. Journal of Atmospheric Chemistry 58(1): 41-53.

Maliselo, S. dan P. Mwaanga. 2016. Effects of $\mathrm{pH}$, moisture and excreta age on ammonia emission in a poultry house: A case study for Kitwe, Zambia. International Journal of Scientific and Research Publications 6(8): 73-76.

Marang. E. A. F., L. D. Mhafudz., T. A. Sarjana dan S. Setyaningrum. Kualitas dan Kadar Amonia Litter Akibat Penambahan Sinbiotik dalam Ransum Ayam Broiler. J. Peternakan Indonesia. 21(3): 303-310

Mayne, R K., P. M. Hocking dan R. W. Else. 2006. Foot pad dermatitis develops at an early age in commercial turkeys. J. British Poultry Sci. 47(1): 36-42.

Metasari, T., D. Septinova, dan V. Wanniatie. 2014. Pengaruh berbagai bahan jenis litter terhadap kualitas litter ayam broiler fase finisher di closed house. J. Ilmiah Peternakan 2 (3): $23-29$.

Nugraha. A. S., H. I. Wahyuni dan E. Widiastuti. 2019. Pengaruh Pemberian Berbagai Level Ekstrak Tomat dalam Air Minum terhadap Bobot Organ Pencernaan Ayam Broiler. Prosiding Seminar Nasional Sumber Daya Pertanian Berkelanjutan dalam Mendukung Ketahanan dan Keamanan Pangan Indonesia pada Era Revolusi Industri 4.0. pp. 62-68.
Rose, S P, 1997. Prinsiples of Poultry Sciences. Harper Adams Agricultural Collag. London.

Sandyawan. A dan A. B. K. Putra. 2019. Studi numerik pengaruh peletakan cooling pad terhadap distribusi temperatur dan pola aliran udara ventilasi kandang ayam broiler closehouse tipe ventilasi Lorong. J. Teknik ITS. 8(2) :150-156

Sarjana, T.A., L.D. Mahfudz, M. Ramadhan, Sugiharto, F. Wahyono dan S. Sumarsih. 2017. Emisi amonia dan kondisi litter pada kandang ayam broiler sistem terbuka yang mendapatkan additif berbeda dan kombinasinya dalam ransum Prosiding Seminar Nasional Pengembangan Peternakan Berkelanjutan ke-9. Tantangan Dunia Peternakan dalam Meningkatkan Nilai Tambah dan Daya Saing Sumber Daya Genetik Ternak Lokal. Jatinangor, Indonesia. pp. 593-599.

Sarjana, T.A., L.D. Mahfudz, D. Winarti, W. Sarenggat, N.K.F. Huda, N.A. Rahma, Renata, D.A. Suryani, W.F. Arfianta dan B. Mustaqim. 2018. Perbedaan kondisi mikroklimat akibat zona penempatan di closed house ayam broiler. Prosiding Seminar Nasional Kebangkitan Peternakan III Hilirisasi Teknologi Peternakan pada Era Revolusi Industri 4. Semarang, Indonesia. pp. 688-700.

Saputra, T. H., K. Nova dan D. Septinova.2015. Pengaruh penggunaan berbagai jenis litter terhadap bobot hidup, karkas, giblet, dan lemak abdominal broiler fase finisher di closed house. J. Ilmiah Peternakan Tepadu 3(1): 38-44.

Saputra, M. R., S. Kismiati dan T. A. Sarjana. 2020. Perubahan mikroklimatik amonia dan kondisi litter ayam broiler periode starter akibat panjang kandang yang berbeda. J. Sains Peternakan 18(1): 7-14

Sims, J.T. dan D. C. Wolf. 1994. Poultry waste management: agricultural and environmental issues. Adv. Agron. (52)183.

Sulaibah, S., T. A. Sarjana dan R. Murawani. 2019. Pengaruh perbedaan panjang kandang dan zona penempatan di dalam kandang closed house terhadap total leukosit dan differensial leukosit ayam broiler. J. Agromedia. 37(1): 86-92. 
Tucker, S. dan A.W. Walker. 1992. Hock burn in broilers. In: Garnsworthy, P.C., Haresign, W., Cole, D.J.A. (Eds.), Recent Advances in Animal Nutrition. ButterworthHeinemann, Oxford. 33- 49.

Wahyuningrum. H. 2020. "Kontribusi Makroklimat di Dataran Berbeda terhadap Perubahan Mikroklimat Closed House".
Skripsi. Fakultas peternakan dan pertanian. Universitas Diponegoro. Semarang.

Zajicek, M dan P. Kic. 2013. Longitudinal ventilation of broiler house-simulation of variants. Jelgava. 24(5): 198-202.

Zuprizal. 2009. Menyiasati Bau Tak Sedap dari kandang. 257. Trobos 